\title{
Building theory of agri-food supply chain resilience using Total Interpretive Structural Modelling and MICMAC analysis
}

\section{Guoqing Zhao*, Shaofeng Liu, Haiyan Lu}

University of Plymouth,

Drake Circus, Plymouth, Devon, PL4 8AA, United Kingdom

Email: guoqing.zhao@plymouth.ac.uk

Email: shaofeng.liu@plymouth.ac.uk

Email: haiyan.lu@plymouth.ac.uk

*Corresponding author

\section{Carmen Lopez}

University of Brighton,

Mithras House, Lewes Road, Brighton, BN2 4AT, United Kingdom

Email: C.Lopez@brighton.ac.uk

\section{Sebastian Elgueta}

Regional Research Center INIA-La Platina

Av Santa Rosa, 11.610, Santiago, Chile

Email: sebastian.elgueta@inia.cl

\begin{abstract}
Agri-food supply chains are inherent with some unique characteristics and that can be easily disrupted compared with other supply chains. Therefore, supply chain resilience factors are relevant and can be taken into consideration. In this paper an attempt has been made to build a theoretical framework of resilience factors in agri-food supply chains with the help of Total Interpretive Structural Modelling and Matrix of Cross Impact Multiplications Applied to Classification analysis. The results of the total interpretive structural modelling demonstrate that leadership plays a vital role in enhancing the resilience of the agri-food supply chain. Furthermore, the matrix of cross impact multiplications applied to classification analysis results indicate that leadership and working team stability along with strong driving power should be given critical focus by agri-food supply chain managers to facilitate the improvement of agri-food supply chain resilience. This paper contributes to the extant theory building in the field of agri-food supply chain resilience, to fill the gap that a few researches have been conducted on agri-food supply chain resilience theory building.
\end{abstract}

Keywords: Agri-food supply chain resilience; Total Interpretive Structural Modelling; MICMAC analysis

Biographical notes: 
This paper is a revised and expanded version of a paper entitled Building theory of agri-food supply chain resilience using total interpretive structural modelling and MICMAC analysis presented at 4th International Conference on Decision Support System Technology, Hellenic Centre for Marine Research, Heraklion, Crete, Greece, 22 - 25 May 2018.

\section{Introduction}

In the last few decades, there has been a growing concern, both from practitioners and academia, that the world's food system for producing and distributing food should be more resilient for various disruptions and risks. Therefore, the research on agri-food supply chain resilience has increased substantially, and researchers and practitioners are showing great interest in it due to its potential impact on reacting to unexpected disruptions and risks (Kamalahmadi and Parast, 2016). While there is a rich body of literature on practices of how to increase agri-food supply chain resilience, the theoretical research on agri-food supply chain resilience is scant. Barratt et al., (2011) argued that adopting theory in research can lead to better conclusions in terms of theoretical framework and insights. In accordance with Barratt et al., (2011), many researchers have tried to build various theories in the field of supply chain management. For example, Macdonald et al., (2018) used structured experimental design combined with discrete-event simulation to build a theory in the area of supply chain risk and resilience. Furthermore, Jain et al., (2017) identified 13 key enablers of resilient supply chain practices and built hierarchical relationships among them using interpretive structural modelling (ISM). Then they use structural equation modelling to validate the hierarchical supply chain resilience model. Attri et al., (2013) stated that ISM is a well-defined methodology for identifying relationships among the selected items by carefully structuring a group of different directly and indirectly related elements into a comprehensive systematic model. However, there have some limitations of the ISM approach. For example, the interpretation of links may be different based on the different users (Sushil, 2012); a limited number of variables can be considered in the development of the ISM model (Attri et al., 2013).

Therefore, Sushil (2012) has adopted a modified version of the ISM called total interpretive structural modelling (TISM), which not only involves various experts to make the interpretive logic of the direct relationship expressed for each paired comparison, but also creates a knowledge base of the interpretive logic of all the relations. In addition, Sandbhor and Brotre (2014) noted that TISM is a powerful technique, which facilitates the development of graphical representations in complicated situations. Due to the multiple advantages of the TISM, therefore, it has been significantly applied as a scientific method for building theory in the field of supply chain management. For example, Shibin et al., (2016) used TISM to build a theory in green supply chain management. Furthermore, Sindhwani and Malhotra (2017) used TISM for identifying the relationships among different factors in an agile manufacturing system. However, there are some limitations for using TISM alone, such as it is difficult for researchers to identify the critical elements that drive the system in different categories (Attri et al., 2013). Matrix of cross impact multiplications applied to classification (MICMAC) analysis provides a supplement for 
Building theory of agri-food supply chain resilience using Total Interpretive Structural Modelling and MICMAC analysis

TISM that can identify critical elements in the system and divide them into different categories (Sharma et al., 1995). Therefore, the integrated approach TISM along with MICMAC analysis will be used in this paper, which not only can identify the relationships among the selected elements, but also can provide precise analysis related to the driving and dependence power of the selected elements.

This study represents an attempt to extend the current agri-food supply chain resilience literature using an alternative research method to fill the gap that a few researches have conducted research on agri-food supply chain resilience theory building. Therefore, the research objectives are as follows: (1) To identify agri-food supply chain resilience factors; (2) To develop a comprehensive agri-food supply chain resilience framework using the TISM combined with the MICMAC analysis. To reach the objectives, the rest of paper is organized as follows. In section two, agri-food supply chain resilience factors are identified through a comprehensive review of the literature. In section three, research methodology is critically discussed. Further, a TISM model and MICMAC analysis of agri-food supply chain resilience factors is presented and discussed in section four. Finally, conclusions are drawn in section five.

\section{Literature review}

Resilience thinking in agri-food supply chain has a high potential to contribute to food security and sustainable food systems (Prosperi et al., 2014). Tendall et al., (2015, p.19) defined food system resilience as "capacity over time of a food system and its units at multiple levels, to provide sufficient, appropriate and accessible food to all, in the face of various and even unforeseen disturbances". Since disturbances are inevitable, therefore, it is necessary for agri-food organisations to embed resilience factors into their daily operations in order to mitigate the effects of disturbances (Pettit et al., 2010). For example, Leat and Revoredo-Giha (2013) highlighted the important role of collaboration in enhancing the resilience of agri-food supply chain after conducting in-depth interviews with seven people involved in the pig supply chain of Scotland. Though considerable studies have looked at agri-food supply chain or their components from a resilience perspective, a few studies have taken the interactions of different resilience factors into consideration (Tendall et al., 2015).

In accordance with the research objectives, this study first identifies the resilience factors in agri-food supply chains, and subsequently develops the relationship among them using TISM and finally classifies them into different groups using MICMAC analysis. Therefore, main resilience factors have been identified in the literatures are: information sharing (Jain et al., 2017), knowledge transfer (Choi and Hong, 2002), innovation and development (Santos-Vijande and Alvarez-Gonzalez, 2007), traceability (Aung and Chang, 2014), joint decision making (Simatupang and Sridharan, 2002), trust (Min et al., 2005), regularly meetings (Kembro et al., 2017), leadership (Demmer et al., 2011) and working team stability (Macdonald et al., 2018). Consistent with previous research of Christopher and Peck (2004), a source that frequently cited as a basis for understanding supply chain resilience (Jain et al., 2017; Kamalahmadi and Parast, 2016; Ponomarov and Holcomb, 2009), the identified resilience factors were categorized into three categories: supply chain collaboration, supply chain risk management (SCRM) culture and visibility.

\subsection{Supply chain collaboration}

Matopoulos et al., (2007) stated that supply chain collaboration is a critical capability for agri-food supply chain partners working effectively with other entities for mutual 
benefits. A high level of collaborative work across the entire supply chain system from strategic level to operational level can significantly help mitigate risk (Christopher and Peck, 2004). A review of literature on supply chain collaboration as it pertains to resilience finds six aspects emphasized: information sharing (Jain et al., 2017), knowledge transfer (Choi and Hong, 2002), joint decision making (Simatupang and Sridharan, 2002), trust (Min et al., 2005), regularly meetings (Kembro et al., 2017), and working team stability (Macdonald et al., 2018).

Information sharing - In today's dynamic and uncertain supply chain environment, sharing the right information with the right supply chain partners has a positive effect on reducing risks in the supply chain (Faisal et al., 2006). Respondents of the survey conducted by Soni et al., (2014) ranked information sharing as the eighth important enabler in building supply chain resilience out of fourteen drivers. Further, to explain the dynamics between various resilient supply chain enablers, Jain et al., (2017) developed a hierarchybased model for supply chain resilience through using ISM. Their research results indicate that information sharing plays a vital role in building a resilient supply chain, which facilitates developing trust and assisting in developing visibility among supply chain partners. Finally, Blackhurst et al., (2011) adopted a theory-building approach based on a multi-industry empirical investigation to explore global supply resiliency. Their study revealed that having pre-defined communication protocols and well-defined communication channels have a positive effect in eliminating confusions among supply chain partners when disruption occurs as information is quickly and efficiently distributed.

Knowledge transfer - Van Wijk et al., (2008, p.832) proposed the definition of interorganisational knowledge transfer as "the process of through which organisational actors - teams, units, or organisations - exchange, receive and are influenced by the experience and knowledge of others". Scholten et al., (2014) empirically investigated the relationship between disaster management and supply chain resilience capabilities using an in-depth qualitative case study methodology. Their research revealed that collaboration, risk awareness, supply chain reengineering and knowledge management form the basis of supply chain resilience capabilities. This was also confirmed by Choi and Hong (2002), their research results indicated that knowledge and a good understanding of the supply chain structure are two important elements of supply chain resilience. Then, in order to have a deep understanding of the supply chain resilience capabilities, Pereira and Silva (2015) conducted a multiple case study to validate ten supply chain resilience factors identified in the literature. The findings suggest that knowledge acquired and built up by managers and employees from their past experience can help them become more capable of mitigating future risks and creating a resilient supply chain.

Joint decision making - Joint decision making is a natural extension of sharing information among independent supply chain members (Stank et al., 2001). Two or more independent supply chain partners working jointly to plan and execute supply chain operations can help to achieve greater success than every member acting in isolation (Simatupang and Sridharan, 2002). Cao et al., (2010, p.6617) defined the joint decision making as "the process where supply chain partners orchestrate decisions in supply chain planning, operations \& solution seeking such as inventory management, demand forecasting or product assortment that optimize supply chain benefits". After investigating eight buyer-supplier relationships in food processing industry, Scholten and Schilder (2015) found that joint-decision making, collaborative communication, mutually created knowledge and joint relationship efforts can help to increase supply chain resilience through enhancing visibility, velocity and flexibility of supply chain. 
Building theory of agri-food supply chain resilience using Total Interpretive Structural Modelling and MICMAC analysis

Trust - According to Min et al., (2005) mutual trust can provide a solid collaborative foundation between supply chain partners and also leads to sharing critical market-based data. However, their research also indicated that building trust among supply chain partners is not easy. Trust can only be obtained after the other member prove their problem-solving abilities and also demonstrate loyalty. After building an information management hierarchy-based model using ISM, Faisal et al., (2007) found that trust can help to facilitate cooperation and collaboration among supply chain partners. Finally, respondents of the survey conducted by Soni et al., (2014) ranked trust as the seventh important enabler in building supply chain resilience out of fourteen drivers.

Regularly meetings - After conducting several interviews with different food manufacturers, Min et al., (2005) proposed that regular meetings between manufacturers and its major customers to discuss various issues such as new item development, package size changes is at the centre of collaboration. For the purpose of building trust and cooperative relationships among supply chain partners, more meetings on a regular basis plays a key role. However, Kembro et al., (2017) revealed that supply chain partners are not likely to meet regularly to discuss how the information was generated and how it should be interpreted, which make it difficult to build strong relationships among supply chain partners.

Working team stability - Working team stability is viewed as a key factor for an effectively operating group (Akgun and Lynn, 2002). Carley (1992) proposed that personnel turnover can reduce overall group performance and competitive advantage due to losing portions of the organization's memory and knowledge as individual leave. Therefore, working team stability plays an important role in keeping the speed of development and competitive advantage of an organisation.

\subsection{SCRM culture}

To create a resilient organization, SCRM culture is critical (Christopher and Peck, 2004). Risk management should be an indispensable part of every organization that is embedded into its corporate culture (Waters, 2007). Two elements mainly prerequisite for building SCRM culture are innovation and development (Santos-Vijande and AlvarezGonzalez, 2007) and leadership (Demmer et al., 2011).

Innovation and development - Innovation and development play a key role for an enterprise's long-term survival and growth, and they also have an important status in how the firms adapt and respond to changes in the unstable business environment (SantosVijande and Alvarez-Gonzalez, 2007). It was found that innovative firms are more likely to establish a desired level of supply chain resilience, an important capability for survival and growth in uncertain times (Christopher, 2005). This was confirmed by Reinmoeller and van Baardwijk (2005), who explored the role of innovation on supply chain resilience, and found that, among the resilient companies they studied, the emphasis on innovation increased by $235 \%$ from 1983 to 2002. In addition, Golgeci and Ponomarov (2013) proposed that a firm's innovativeness plays a critical role in achieving supply chain resilience. Their empirical research results indicate that firm innovativeness and innovation magnitude have a positive correlation with supply chain resilience. Furthermore, it was also found in their research that disruption severity is positively associated with innovation magnitude.

Leadership - Demmer et al., (2011) proposed that top management's support plays a key role in engendering innovation in the context of small and medium-sized companies. In addition, Faisal et al., (2007) stated that top management's support has a positive effect 
in generating supply chain wide strategies and changing incentive alignment. Christopher and Peck (2004) stated that nothing is impossible without the support and commitment from the leadership in the process of cultural change in the organizations. After conducting a multi-industry empirical investigation, Blackhurst et al., (2011) stated that educating and training employees was identified by six firms as a critical factor in enhancing supply chain resilience, while educating and training employees need top management's support.

\subsection{Visibility}

Visibility has been defined by Francis (2008, p.182) as "the identity, location and status of entities transiting the supply chain, captured in timely messages about events, along with the planned and actual dates/times of these events". Visibility as a driver of resilience, it plays a key role in mitigating the effects of disruptions (Kamalahmadi and Parast, 2016). A review of literature identified traceability (Aung and Chang, 2014) as an important part for achieving visibility in agri-food supply chain.

Traceability - Bosona and Gebresenbet (2013, p.35) proposed an informative and comprehensive definition of traceability as: "a part of logistics management that capture, store, and transmit adequate information about a food, feed, food-producing animal or substance at all stages in the food supply chain so that the product can be checked for safety and quality control, traced upward, and tracked downward at any time". A good traceability system in the agri-food supply chain plays a critical role in minimizing the risk of production and distribution of unsafe or poor quality products, as well as to reduce the response time to deal with food scandals and incidents (Aung and Chang, 2014). After conducting a systematic literature review on food traceability, Ringsberg (2014) found that the implementation of food traceability in agri-food supply chain not only has a positive effect in ensuring food safety, but also can help to increase supply chain resilience.

\section{Research methodology}

Research methodology includes several tools used for data collection and analysis to investigate a certain issue (Charmaz, 2014). Thus, this section would explain the data collection and analysis methods that are used in this study, and why they have been selected over other methods available. Tashakkori and Teddlie (2008) noted that selecting appropriate research methods are very critical when conducting scientific research.

Face-to-face semi-structured interviews were selected as the data collection method because it can help researchers to acquire more detailed information from practitioners, not only from what is said, but also from the visual cues and gestures made when interviewees reply to questions (Maxim, 1999). Robson (2002) stated that semi-structured interviews could be used to understand the relationships between variables in an explanatory study, or it can be very helpful to find out what is happening and to seek new insights in an exploratory study.

The data analysis method used in this paper is a combination of thematic analysis, TISM and MICMAC analysis. Each analysis result will be served as an input to process another analysis. Firstly, thematic analysis not only can provide a detailed descriptive summary of the analysis, but also can interpret how the research findings have cast light on the issue in hand (Braun and Clarke, 2006). Secondly, TISM is a qualitative and interpretive method, which generate solutions for complicated problems through a set of various directly and indirectly related elements are structured into a comprehensive systematic model (Sushil, 2012). This method adopted in this paper was used to build 
Building theory of agri-food supply chain resilience using Total Interpretive Structural Modelling and MICMAC analysis

hierarchical relationships among the agri-food supply chain resilience factors, so that the influence of each factor can be analysed. Finally, the MICMAC analysis is used to assess the driving power and dependence power of agri-food supply chain resilience factors. Attri et al., (2013) stated that MICMAC analysis is an indirect classification method to critically analyse the scope of every element.

In the next two sub-sections, we critically discussed how semi-structured interview can be implemented as the data collection method and why thematic analysis, TISM and MICMAC analysis are the optimal choices for this study.

\subsection{Data collection method}

This section illustrates in detail how the interview was prepared and how the interview data were collected.

\subsubsection{Sampling technique}

There are two main sampling categories: probability sampling and non-probability sampling. Saunders et al., (2012) stated that probability sampling are mainly used for answering the research questions or reflecting a phenomenon from a general perspective, while non-probability sampling are mainly used for generating results from a specific perspective. As this study was focuses on the resilience factors in agri-food supply chain, non-probability sampling is more suitable. Thus, the sampling strategies in this study are purposive sampling and snowball sampling. In purposive sampling, participants were selected based on the pre-selected criteria, who would be the suitable interviewees to answer the research questions. Furthermore, two experts from academia and agri-food industry were consulted to reduce bias and make the pre-selected criteria more comprehensive. In the following, the pre-selected criterion is listed:

(1) The interviewee should be from the agri-food industry covering any of the agri-food supply chain categories such as agri-chemical producer, farmer, food manufacturer, wholesaler, logistics service provider, and retailer;

(2) The agri-food company must be at least medium-sized (from 10 to 249 employee) or large-sized company (more than 249 employees) because these companies not only have rich experience in continuously managing their supply chains, but also have deep understanding on increasing supply chain resilience and reducing supply chain risks;

(3) Interviewee range includes supply chain managers, operation managers, executive chief (with more than ten years working experience);

(4) The company should provide permission to access its key information.

As for the snowball sampling, each participant was asked towards the end of the interview, whether they knew anyone who is knowledgeable about the phenomenon of agri-food supply chain resilience. Thus, recommendations would be taken from interviewees to select a suitable person to answer the research questions.

Creswell and Poth (2018) recommended including 20 to 30 interviews in order to develop a well-saturated theory. Furthermore, Saunders et al., (2012) suggested continuingly collecting qualitative data by conducting extra interviews until the additional collected data provides few new insights. However, Charmaz (2014) argued that 30 interviews may be much larger, data becomes repetitive. Thus, owing to this study is to explore and build a theory of agri-food supply chain resilience, data saturation was not 
reached on less than 30 semi-structured interviews since new resilience factors were explored based on the roles of company in the agri-food supply chain network.

\subsubsection{Conducting interviews}

The interviews were conducted in different countries (United Kingdom, France, Spain, Italy and Argentina) over a period of 14 months from April 2017 to July 2018. The interview time ranged from 60 minutes to 90 minutes, depending on the interviewee's schedule and availability. The detailed information of the interviewees is shown in Table 1. Ethical issues such as requiring consent forms, ensuring privacy, confidentially, anonymity and recording the interviews were carefully considered. Furthermore, permission of audio recordings was requested at the beginning of the interview. Saunders et al., (2012) proposed that there are several benefits for recording interviews, such as allowing the interviewer to focus on questioning and listening and increasing the reliability and validity of the research.

Table 1 The detailed information of interviewees

\begin{tabular}{|c|c|c|c|c|}
\hline Category & Country & Company type & Quantity & Interview \\
with
\end{tabular}

The researcher started the interview by introducing himself and giving an overall introduction of the research conducted. Then, the researcher asked some general questions about the company and the interviewee such as the number of people working in this company, the core business of the company and the number of years he/she has spent in the company. In the interview process, interviewees were free to express themselves on 
Building theory of agri-food supply chain resilience using Total Interpretive Structural Modelling and MICMAC analysis

any asked questions. Then, specific questions related to agri-food supply chain risks and resilience were asked such as the sources of risks that affect the company and the strategies that the company adopted to build resilience against agri-food supply chain risks. Finally, some open-ended questions were asked such as the outcomes of implementing those resilience strategies to get more data, themes and attitudes towards some specific issues that may be useful when analysing the collected data.

\subsection{Data analysis methods}

In order to have a deep understanding on the phenomenon of agri-food supply chain resilience, the data analysis process was carried out in three steps: firstly, thematic analysis was used to match the raw data with the main themes, secondly, TISM was used to define the relationships among the identified resilience factors, thirdly, MICMAC analysis was used to divide different resilience factors into different groups. Detailed explanation of each data analysis method is shown in the next few sub-sections.

\subsubsection{Thematic analysis}

To get accurate and meaningful data analysis results, thematic analysis was used for matching qualitative data with various themes. Braun and Clark (2006) stated that thematic analysis is a foundational approach used to identify, extract, analyse and report themes within the collected textual material.

\subsubsection{TISM}

TISM is a methodology which enables individuals to build hierarchical relationships among various elements in a complex system (Sushil, 2012). In this paper, we have adopted the process of TISM proposed by Sushil (2012). The various steps involved in the TISM methodology are as follows:

(1) Identification of variables: the variables of the system which are relevant to the problem or issue are identified, as well as a series of problem-solving technique such as brainstorming session is adopted in this process.

(2) Define contextual relationship: the variables identified in step (1), a contextual relationship is identified among each variable with respect to which pairs of variables would be examined. Then, a structural self-interaction matrix (SSIM) is prepared based on a pair-wise comparison of the variables of the system under consideration.

(3) Interpretation of relationship: This step of TISM is better than traditional ISM, as the former seeks to clarify the interpretation of the relationship. In the context of this study, the interpretation will be "in what way enabler A will help to achieve enabler B?" It will help to get in-depth knowledge explicit.

(4) Interpretive logic of pair-wise comparison: An "Interpretive Logic-Knowledge Base" can be established for pair-wise comparison of the variables to fully interpret each paired comparison and know how that directional relationship operates in the system; the answer for each comparison may be "yes" or "no". If the answer is "yes", further interpretation is necessary. In the context of this study, 72 paired comparisons needed to be considered.

(5) Reachability matrix and transitivity check: The reachability matrix is built through the entries 1 for "yes" and 0 for "no" from the interpretive logic-knowledge base. The matrix is checked for the transitivity rule (if $\mathrm{A}$ is related to $\mathrm{B}$ and $\mathrm{B}$ is related to $\mathrm{C}$, then $\mathrm{A}$ is necessarily related to $\mathrm{C}$ ). 
(6) Level partition on reachability matrix: Level partitioning is carried out similar to the ISM methodology. All variables considered in this study would be arranged into different levels.

(7) Developing digraph: The elements are portrayed in the form of a directed graph, where the elements are arranged according to the levels, and relationships are portrayed from the reachability matrix. Those transitive links whose interpretation is crucial, are retained.

(8) Interaction matrix: A binary matrix is developed by translating the final digraph using 1 to indicate direct and significant transitive links. It is further developed as an interpretive matrix by providing the relevant interpretation from the knowledge base.

(9) Total interpretive structural model: The connective information from the digraph and interpretations from the interaction matrix are used to develop the TISM. The nodes in the digraph are replaced by interpretations provided in the interaction matrix.

\subsubsection{MICMAC analysis}

Matriced 'Impacts croises-multipication applique' and classment (cross-impact matrix multiplication applied to classification) is abbreviated as MICMAC. The purpose of MICMAC analysis in this study is to analyse the driving and dependence power of factors under consideration and to identify the key factors that drive the system in various categories (Attri et al., 2013). Simultaneously, it gives some valuable insights about the relative importance and interdependencies among the identified factors (Jain et al., 2017). Based on their driving and dependence power, the factors can be divided into four groups: (1) Autonomous variables include elements that have weak driving power and weak dependence power; (2) Dependent variables include elements that have weak driving power and strong dependence power; (3) Linkage variables include elements that have strong driving power and strong dependence power; (4) Finally, independent variables include elements that have strong driving power and weak dependence power.

\section{Data analysis and discussion}

The process of how to apply thematic analysis, TISM and MICMAC analysis in the context of agri-food supply chain resilience is described in this section.

\subsection{Thematic analysis}

Thematic analysis was used to analyse the qualitative data collected through face-toface semi-structured interviews with agri-food supply chain managers from large-sized companies in the agri-food supply chain. The thematic analysis is used to allow agri-food supply chain resilience themes generated, as well as to confirm existing themes from the transcripts and documents. Various themes were generated through three processes of thematic analysis: descriptive coding, interpretative coding and defining main themes (King and Horrocks, 2010). In this study, in order to ensure the accuracy of the interview results and prevent any omissions, the audio recordings were transcribed word by word, and transcripts were carefully edited to remove irrelevant terms and duplicated words. Simultaneously, another two authors were involved in this process in order to reduce bias. The detailed information of each process was demonstrated in the following:

(1) Descriptive coding (first-order codes): the researchers classify the transcribed data from interviews that allocate descriptive codes and help to answer the research questions; 
Building theory of agri-food supply chain resilience using Total Interpretive Structural Modelling and MICMAC analysis

(2) Interpretative coding (second-order themes): the allocated descriptive groups which seem to have the same meanings are classified into the same group so as to create an interpretive code;

(3) Defining the main themes (aggregate dimensions): overarching themes that can describe the main concepts in the analysis are identified.

Finally, the initial resilience factors identified in the literature review were refined through integrating and summarizing the empirical findings (Table 2).

Table 2 Agri-food supply chain resilience capabilities data structure table

\begin{tabular}{|c|c|}
\hline First order codes & $\begin{array}{l}\text { Aggregate } \\
\text { dimensions }\end{array}$ \\
\hline $\begin{array}{l}\text { "There is another project trying to make different producers } \\
\text { working together". } \\
\text { "There is some training courses depend on what producers } \\
\text { need. Producers may ask or demand from trainings, so we } \\
\text { can organise training courses". }\end{array}$ & $\begin{array}{c}\text { Innovation and } \\
\text { development }\end{array}$ \\
\hline $\begin{array}{l}\text { "There have been a number of positive impacts of } \\
\text { information sharing, for example, the irrigation technique to } \\
\text { watering the plants. Thanks to the sharing of information, } \\
\text { some producers what they did is to move to another field } \\
\text { once they find the water is not good". }\end{array}$ & Information sharing \\
\hline $\begin{array}{l}\text { "Not through individual assistance, only by confirming } \\
\text { groups of producers. Visit all the farms and monthly meeting } \\
\text { with farmers". }\end{array}$ & Regularly meetings \\
\hline $\begin{array}{l}\text { "Producers trust us because we are technicians, we try to help } \\
\text { producers... The producer trusts us because we have been } \\
\text { working together with them for a long time, and tries to help } \\
\text { them with technical things". }\end{array}$ & Trust \\
\hline $\begin{array}{l}\text { "Large producers are more likely to have this traceability } \\
\text { technology because they sell through specific channels that } \\
\text { required traceability". }\end{array}$ & Traceability \\
\hline "Do they make decision together? Yes". & Joint decision making \\
\hline $\begin{array}{l}\text { "We use education technology in order to know how to } \\
\text { transfer the knowledge in a way that farmers would be able } \\
\text { to understand". }\end{array}$ & Knowledge transfer \\
\hline $\begin{array}{l}\text { "We always work together because we are familiar with each } \\
\text { other and we can talk with each other freely". }\end{array}$ & $\begin{array}{l}\text { Working team } \\
\text { stability }\end{array}$ \\
\hline $\begin{array}{l}\text { "Our leaders' support is very important for coordinating and } \\
\text { collaborating with each other. We can get money to do things } \\
\text { if we got their permission". }\end{array}$ & Leadership \\
\hline
\end{tabular}

\subsection{TISM model development}

Since the factors considered in this study positively affect agri-food supply chain resilience, it is ideal to increase their occurrence and effect during the agri-food supply chain. However, all of these resilience factors under consideration cannot be given equal attention by the agri-food supply chain managers since it is practically not feasible. 
Therefore, efforts in increasing their effects or occurrence at the root level thus need to be carefully managed. This can be achieved through using TISM to identify their relationships of these factors with one another and with overall resilience to optimize efforts. In the following sections, how to build TISM resilience model step-by-step is shown.

\subsubsection{Structural self-interaction matrix (SSIM)}

The resilience factors identified in the systematic literature review are used to establish the contextual relationship among variables. The existence of a relation between any two variables and the associated direction of the relation is consulted with a group of experts from academia and agri-food industry. The two parameters amongst which the relationship, represented and checked by $\mathrm{i}$ and $\mathrm{j}$. Four symbols $\mathrm{V}, \mathrm{A}, \mathrm{X}, \mathrm{O}$ are used to indicate the direction between any two variables (i and j) (Sushil, 2012):

(1) V-When i leads to $\mathrm{j}$ but $\mathrm{j}$ does not lead to $\mathrm{i}$;

(2) A-When $\mathrm{j}$ leads to $\mathrm{i}$ but $\mathrm{i}$ does not lead to $\mathrm{j}$;

(3) X-When i leads to $\mathrm{j}$ and $\mathrm{j}$ leads to $\mathrm{i}$;

(4) O-If the relation between the elements does not appear valid.

Based on the opinion of experts, the existing relationships between any two supply chain resilience enablers are presented in SSIM as shown in Table 3; here enablers on the left are considered as " $\mathrm{i}$ " and enablers on top are considered as " $\mathrm{j}$ ".

Table 3 Structural self-interaction matrix of agri-food supply chain resilience enablers

\begin{tabular}{|l|c|c|c|c|c|c|c|c|c|}
\hline & E9 & E8 & E7 & E6 & E5 & E4 & E3 & E2 & E1 \\
\hline E1-Knowledge transfer & A & A & A & A & X & O & V & A & X \\
\hline E2-Working team stability & A & V & V & V & V & O & V & X & V \\
\hline E3-Innovation and development & A & A & A & A & X & V & X & A & A \\
\hline E4-Traceability & A & O & A & O & V & X & A & O & O \\
\hline E5-Information sharing & A & A & A & A & X & A & X & A & X \\
\hline E6-Joint decision making & A & A & X & X & V & O & V & A & V \\
\hline E7-Trust & A & X & X & X & V & V & V & A & V \\
\hline E8-Regularly meetings & A & X & X & V & V & O & V & A & V \\
\hline E9-Leadership & X & V & V & V & V & V & V & V & V \\
\hline
\end{tabular}

\subsubsection{Reachability matrix}

The SSIM matrix is further converted into the initial reachability matrix by substituting the four symbols (V, A, X, O) of SSIM into 1's and 0's in the reachability matrix (see Table 4). The transformation is based on the rules demonstrated in the following (Sushil, 2012):

(1) If the $(i, j)$ entry in the SSIM is $V$, the $(i, j)$ entry in the reachability matrix becomes 1 and the $(\mathrm{j}, \mathrm{i})$ entry becomes 0 ;

(2) If the $(i, j)$ entry in the SSIM is A, the $(i, j)$ entry in the reachability matrix becomes 0 and the $(\mathrm{j}, \mathrm{i})$ entry becomes 1 ;

(3) If the $(i, j)$ entry in the SSIM is $X$, the $(i, j)$ entry in the reachability matrix becomes 1 and the $(j, i)$ entry also becomes 1 ;

(4) If the $(i, j)$ entry in the SSIM is $O$, the $(i, j)$ entry in the reachability matrix becomes 0 and the $(\mathrm{j}, \mathrm{i})$ entry also becomes 0 .

Table 4 Initial reachability matrix 
Building theory of agri-food supply chain resilience using Total Interpretive Structural Modelling and MICMAC analysis

\begin{tabular}{|c|c|c|c|c|c|c|c|c|c|}
\hline & E1 & E2 & E3 & E4 & E5 & E6 & E7 & E8 & E9 \\
\hline E1 & 1 & 0 & 1 & 0 & 1 & 0 & 0 & 0 & 0 \\
\hline E2 & 1 & 1 & 1 & 0 & 1 & 1 & 1 & 1 & 0 \\
\hline E3 & 0 & 0 & 1 & 1 & 1 & 0 & 0 & 0 & 0 \\
\hline E4 & 0 & 0 & 0 & 1 & 1 & 0 & 0 & 0 & 0 \\
\hline E5 & 1 & 0 & 1 & 0 & 1 & 0 & 0 & 0 & 0 \\
\hline E6 & 1 & 0 & 1 & 0 & 1 & 1 & 1 & 0 & 0 \\
\hline E7 & 1 & 0 & 1 & 1 & 1 & 1 & 1 & 1 & 0 \\
\hline E8 & 1 & 0 & 1 & 0 & 1 & 1 & 1 & 1 & 0 \\
\hline E9 & 1 & 1 & 1 & 1 & 1 & 1 & 1 & 1 & 1 \\
\hline
\end{tabular}

After incorporating the transitivity, as mentioned in step 5 of the TISM methodology, the final reachability matrix that includes the transitivity, driving power and dependence power for each criterion is shown in Table 5. Transitivity property helps to remove the gaps among the variables in the system if any (Shibin et al., 2016).

Table 5 Final reachability matrix

\begin{tabular}{|c|c|c|c|c|c|c|c|c|c|c|}
\hline & E1 & E2 & E3 & E4 & E5 & E6 & E7 & E8 & E9 & $\begin{array}{c}\text { Driving } \\
\text { power }\end{array}$ \\
\hline E1 & 1 & 0 & 1 & $1^{*}$ & 1 & 0 & 0 & 0 & 0 & 4 \\
\hline E2 & 1 & 1 & 1 & $1^{*}$ & 1 & 1 & 1 & 1 & 0 & 8 \\
\hline E3 & $1^{*}$ & 0 & 1 & 1 & 1 & 0 & 0 & 0 & 0 & 4 \\
\hline E4 & 0 & 0 & 0 & 1 & 1 & 0 & 0 & 0 & 0 & 2 \\
\hline E5 & 1 & 0 & 1 & 0 & 1 & 0 & 0 & 0 & 0 & 3 \\
\hline E6 & 1 & 0 & 1 & 0 & 1 & 1 & 1 & $1^{*}$ & 0 & 6 \\
\hline E7 & 1 & 0 & 1 & 1 & 1 & 1 & 1 & 1 & 0 & 7 \\
\hline E8 & 1 & 0 & 1 & 0 & 1 & 1 & 1 & 1 & 0 & 6 \\
\hline E9 & 1 & 1 & 1 & 1 & 1 & 1 & 1 & 1 & 1 & 9 \\
\hline $\begin{array}{c}\text { Dependence } \\
\text { power }\end{array}$ & 8 & 2 & 8 & 6 & 9 & 5 & 5 & 5 & 1 & \\
\hline
\end{tabular}

\subsubsection{Partitioning the reachability matrix into different levels}

The reachability set consists of the variable itself and the other variables that it may influence, whereas the antecedent set consists of the variable and the other variables that may influence it. The intersection of the reachability set and the antecedent set will be the same as the reachability set if the variable occupies the top level in the TISM hierarchy. The top-level variables satisfying the above requirements should be removed from the reachability set and the antecedent set. Then, the same process is repeated till all the levels are determined (Sushil, 2012). The table of partitioning the reachability matrix into different levels is demonstrated in Table 6:

Table 6 Partitioning the reachability matrix into different levels

\begin{tabular}{|c|c|c|c|c|}
\hline Variable & Reachability Set (RS) & Antecedent Set (AS) & ASกRS & Level \\
\hline Iteration 1 & & & & \\
\hline E1 & $1,3,4,5$ & $1,2,3,5,6,7,8,9$ & $1,3,5$ & \\
\hline E2 & $1,2,3,4,5,6,7,8$ & 2,9 & 2 & \\
\hline
\end{tabular}




\begin{tabular}{|c|c|c|c|c|}
\hline E3 & $1,3,4,5$ & $1,2,3,5,6,7,8,9$ & $1,3,5$ & \\
\hline E4 & 4,5 & $1,2,3,4,7,9$ & 4 & \\
\hline E5 & $1,3,5$ & $1,2,3,4,5,6,7,8,9$ & $1,3,5$ & Level I \\
\hline E6 & $1,3,5,6,7,8$ & $2,6,7,8,9$ & $6,7,8$ & \\
\hline E7 & $1,3,4,5,6,7,8$ & $2,6,7,8,9$ & $6,7,8$ & \\
\hline E8 & $1,3,5,6,7,8$ & $2,6,7,8,9$ & $6,7,8$ & \\
\hline E9 & $1,2,3,4,5,6,7,8,9$ & 9 & 9 & \\
\hline Iteration 2 & & & & \\
\hline E1 & $1,3,4$ & $1,2,3,6,7,8,9$ & 1,3 & \\
\hline E2 & $1,2,3,4,6,7,8$ & 2,9 & 2 & \\
\hline E3 & $1,3,4$ & $1,2,3,6,7,8,9$ & 1,3 & \\
\hline E4 & 4 & $1,2,3,4,7,9$ & 4 & Level II \\
\hline E6 & $1,3,6,7,8$ & $2,6,7,8,9$ & $6,7,8$ & \\
\hline E7 & $1,3,4,6,7,8$ & $2,6,7,8,9$ & $6,7,8$ & \\
\hline E8 & $1,3,6,7,8$ & $2,6,7,8,9$ & $6,7,8$ & \\
\hline E9 & $1,2,3,4,6,7,8,9$ & 9 & 9 & \\
\hline Iteration 3 & & & & \\
\hline E1 & 1,3 & $1,2,3,6,7,8,9$ & 1,3 & Level III \\
\hline E2 & $1,2,3,6,7,8$ & 2,9 & 2 & \\
\hline E3 & 1,3 & $1,2,3,6,7,8,9$ & 1,3 & Level III \\
\hline E6 & $1,3,6,7,8$ & $2,6,7,8,9$ & $6,7,8$ & \\
\hline E7 & $1,3,6,7,8$ & $2,6,7,8,9$ & $6,7,8$ & \\
\hline E8 & $1,3,6,7,8$ & $2,6,7,8,9$ & $6,7,8$ & \\
\hline E9 & $1,2,3,6,7,8,9$ & 9 & 9 & \\
\hline Iteration 4 & & & & \\
\hline E2 & $2,6,7,8$ & 2,9 & 2 & \\
\hline E6 & $6,7,8$ & $2,6,7,8,9$ & $6,7,8$ & Level IV \\
\hline E7 & $6,7,8$ & $2,6,7,8,9$ & $6,7,8$ & Level IV \\
\hline E8 & $6,7,8$ & $2,6,7,8,9$ & $6,7,8$ & Level IV \\
\hline E9 & $2,6,7,8,9$ & 9 & 9 & \\
\hline Iteration 5 & & & & \\
\hline E2 & 2 & 2,9 & 2 & Level V \\
\hline E9 & 2,9 & 9 & 9 & \\
\hline Iteration 6 & & 9 & & \\
\hline E9 & 9 & & 9 & Level VI \\
\hline & & & \\
\hline
\end{tabular}

\subsubsection{Diagraph with significant transitive links}

The variables are arranged into different levels and the directed and significant transitive links are demonstrated as per the relationships observed in the reachability matrix. The digraph established may have cycles at a specific level and feedbacks across the different levels between elements. Normally, the feedbacks and cycles should be eliminated to get minimum edges; but the same should be retained in the matrix if the intention is to further explore the impact of indirect relationships between the elements (Sushil, 2012).

\subsubsection{TISM model of the agri-food supply chain resilience factors}


Building theory of agri-food supply chain resilience using Total Interpretive Structural Modelling and MICMAC analysis

Figure 2 below shows the TISM model of resilience factors of agri-food supply chains. Information sharing (E5), traceability (E4), knowledge transfer (E1) and innovation and development (E3) occupied the level I, level II and level III of the model separately. Joint decision making (E6), trust (E7) and regularly meetings (E8) are coming at the fourth level, which shows the critical role of trust for facilitating better collaboration and cooperation among supply chain partners. Working team stability (E2) and leadership (E9) are at the level V and level VI separately. The TISM model demonstrates that to enhance the resilience of the agri-food supply chain, leadership is vital. This will facilitate developing a stable team working together through support and commitment from the leadership. In a stable working team, team members understanding each other's needs and satisfy the needs accordingly, which have a positive effect on developing trust among team members. Team members that are familiar with each other facilitate sharing critical information and transferring knowledge among each other, thus, it will be easier to communicate and coordinate with each other. Furthermore, team members always complete the same task and solve the problem together, this will assist the whole team to make the decision together and have meetings regularly. In the meeting and decision-making process, supply chain partners talk to each other, problems and challenges are openly discussed, and thus facilitate knowledge transfer among partners. Therefore, the innovation capacity of partners is enhanced because transfer knowledge among partners which has a positive effect in reducing innovation cost. In the knowledge transfer process, supply chain partners will realize the key role of traceability in building agri-food supply chain resilience. Simultaneously, innovation cost will be decreased, and traceability technology will be applied with the development of knowledge transfer. Then, they will share traceability data with other supply chain partners. As a result, the information sharing among supply chain members will be enhanced. Clear understanding of the transitive linkages among the resilience factors helps clearly depict the actions that are to be taken to attain the desired level in the hierarchy. The results show that leadership (E9) and working team stability (E2) will influence the knowledge transfer (E1) and innovation and development (E3) programs in a supply chain. 


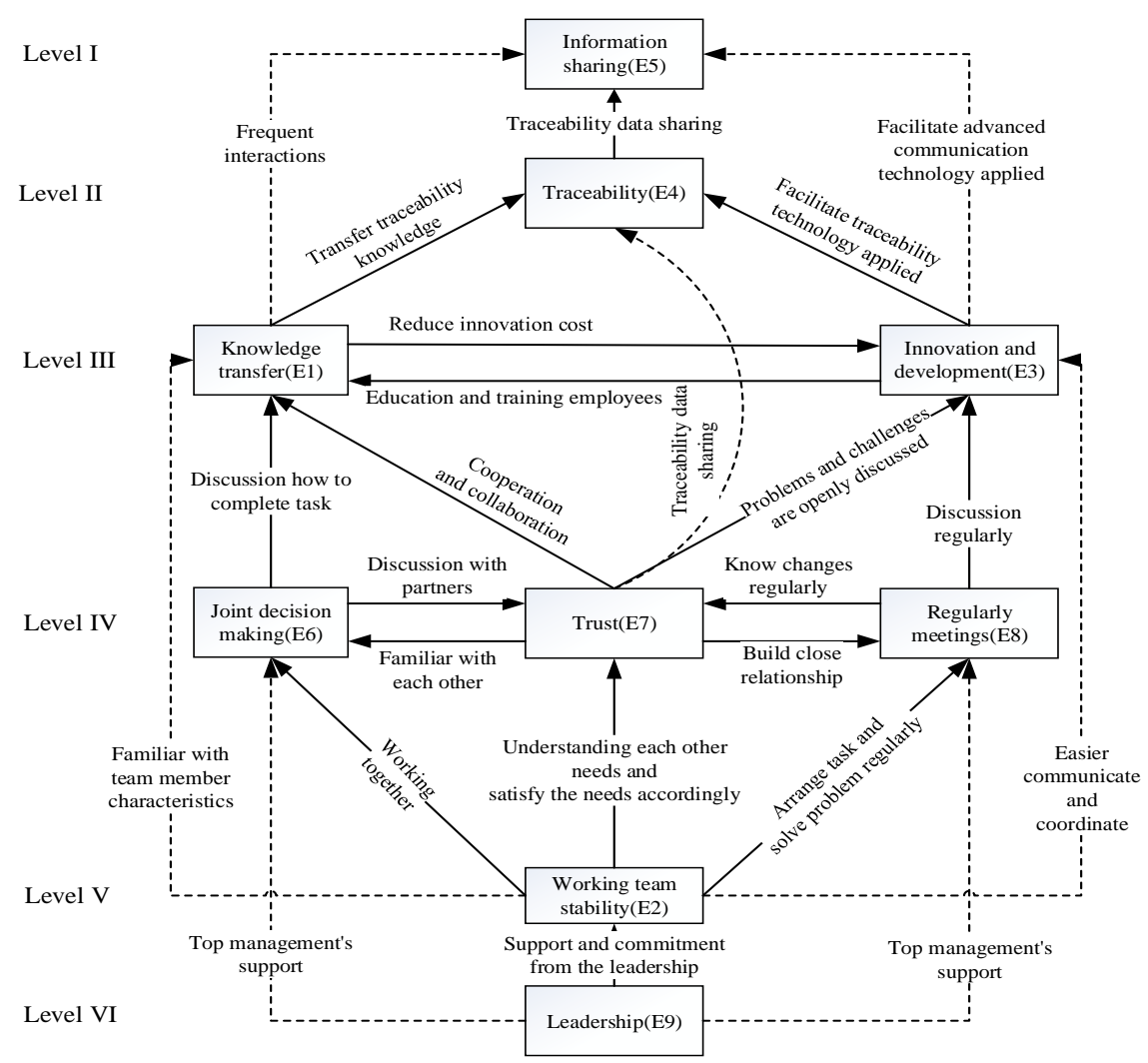

Figure 2 TISM model of agri-food supply chain resilience factors

\subsection{MICMAC analysis results}

Comparing the hierarchy of resilience factors in the different classifications can help to get a rich source of information. The driving and dependence power diagram (Figure 3) is constructed with the input from the final reachability matrix (Table 5). In Figure 3, the driving power is represented as the vertical axis and the dependence power as horizontal axis. Then, the nine agri-food supply chain resilience factors are plotted on the diagram to demonstrate their association with the driving and dependence power. Identified resilience factors are classified into four groups: autonomous, dependent, linkage and independent.

Results from Figure 3 below show the MICMAC analysis of the agri-food supply chain resilience factors. The MICMAC analysis shows that all the resilience factors considered in this study are necessary to explain the theoretical framework of the agri-food supply chain resilience as there are no autonomous variables. Autonomous resilience factors are weak driving power and weak dependence power. As the autonomous variables are relatively disconnected from the system, they do not have much influence on the system. Therefore, among the nine selected resilience factors, all the factors have much influence on the agri-food supply chain resilience implementation. Hence, supply chain managers cannot take lightly any of these resilience factors because they are very helpful in making agri-food supply chain more resilient. 
Building theory of agri-food supply chain resilience using Total Interpretive Structural Modelling and MICMAC analysis

MICMAC analysis results also shows that joint decision making (E6), trust (E7), regularly meetings (E8) are linkage variables in the framework and are characterized by their strong driving power and strong dependence power. These variables are highly sensitive, thus, any change in the system or other variables will affect these linkage variables.

The driving power and dependence power diagram (Figure 2) indicates that leadership (E9) and working team stability (E2) are independent variables because they are characterized by high driving power and low dependence power. Thus, these resilience factors should be given a critical focus by agri-food supply chain managers to avoid the effect of dependent variables. It has been observed that these resilience factors have a positive effect in achieving other resilience factors which appear at the bottom of TISM hierarchy. Therefore, supply chain managers should work out some strategies to facilitate that these independent resilience factors are implemented in agri-food supply chains.

The dependent variables like knowledge transfer (E1), innovation and development (E3), traceability (E4) and information sharing (E5) that have a weak driving power and strong dependence power form the top level in the TISM hierarchy. Their strong dependence indicates that they require all the other resilience factors to minimize the effect of these dependent variables on the supply chain resilience strategies' implementation. Therefore, the supply chain managers should put high priority on dealing with these resilience factors.

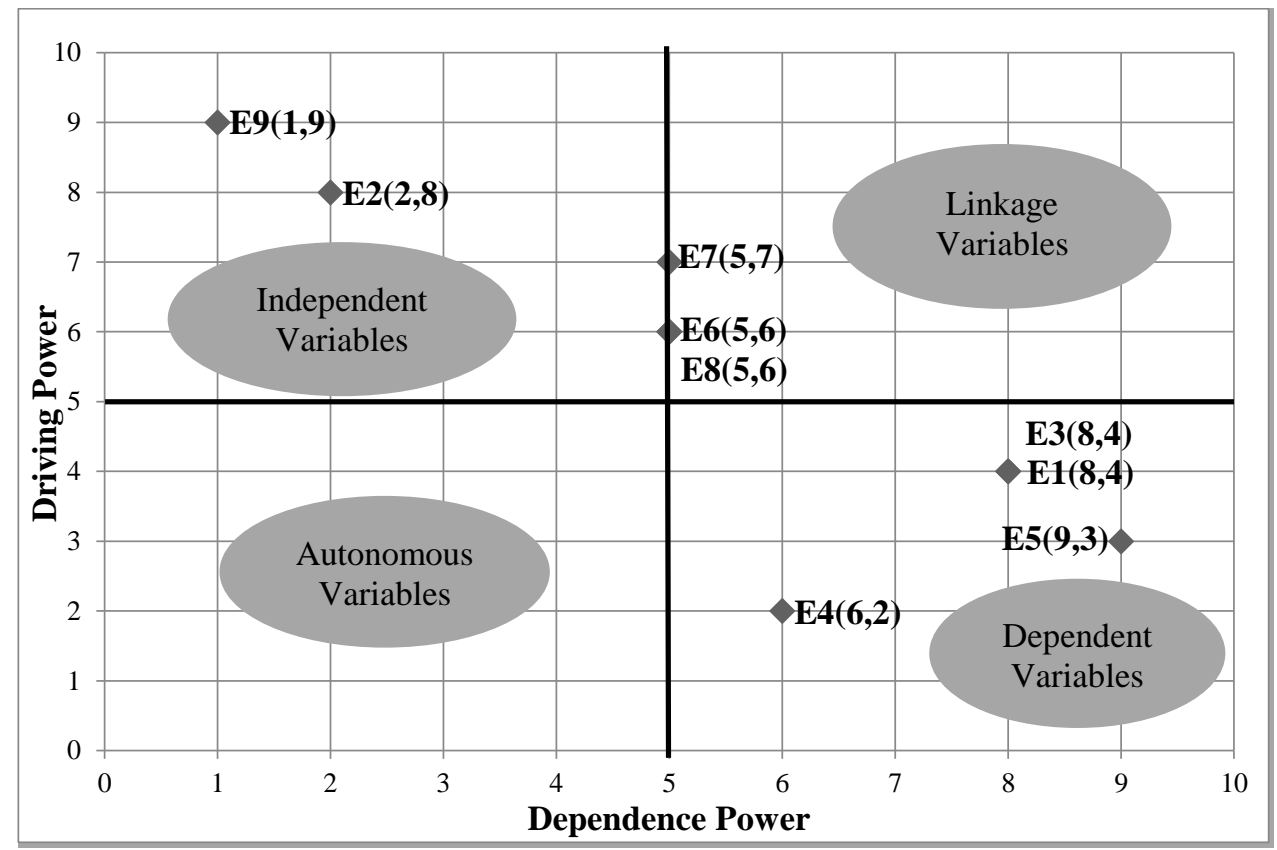

Figure 3 MICMAC analysis of the agri-food supply chain resilience factors

\section{Conclusion}

In this paper, an attempt has been made to build a theoretical framework of resilience factors of the agri-food supply chain by using thematic analysis, TISM and MICMAC 
analysis. Thematic analysis was used to identify the resilience factors from the qualitative data collected through semi-structured interviews. Then, TISM was used to identify the interactions and transitive links among the resilience factors of agri-food supply chain. The results of TISM are used as an input to process MICMAC analysis. Finally, the MICMAC analysis was used to divide different resilience factors into various groups. The MICMAC analysis results indicate the various categories of the resilience factors that need attention by supply chain managers according to their driving and dependence power. Supply chain managers should focus on those resilience factors that have a higher driving power because these resilience factors play a critical role in achieving agri-food supply chain resilience. Once these higher driving power resilience factors have been identified, supply chain managers need to formulate strategies for enhancing their effects during the supply chain resilience strategies implementation. In addition, the identification and classification of resilience factors may be helpful for supply chain managers to employ this model in order to identify and classify the most important resilience factors for their needs, and to reveal the direct and indirect effects of each resilience factor on the agri-food supply chain resilience strategies implementation.

This research has a number of contributions to build agri-food supply chain resilience. Firstly, it identifies and categorizes different resilience factors based on the literature review and empirical evidence from five countries. Therefore, practitioners can focus on the key determinants for building the resilient agri-food supply chain; secondly, it inform supply chain managers about the most important resilience factors (leadership and working team stability) and how these resilience factors influence each other for achieving resilient agri-food supply chain success; thirdly, this is the first TISM model of resilience factors dedicated to building resilience in the agri-food supply chain.

However, this study does have some limitations. Firstly, the interviewees cover all the main actors in the agri-food supply chain, such as farmers, manufacturers, markets, there was no interviewees from packaging companies, field test companies and regional agriculture department/agencies; secondly, only two and five interviews were conducted in the UK and Spain separately, the empirical study was not enough in these two countries; thirdly, only binary type of relations among different resilience factors have been considered, there is no scope for discussion about the strength of relationship. Thus, there is a clear need to develop more systematic approaches and techniques for a holistic view of the resilience factors in the agri-food supply chain. Suggestions for future research include:

(1) The interviewees from packaging companies, field test companies and regional agriculture department/agencies should be considered in the future research;

(2) More interviews can be conducted in the UK and Spain with different actors in the agrifood supply chain;

(3) Fuzzy set theory can be adopted in the data analysis process in the future research by qualitative consideration on a $0-1$ scale to accurately analyse the relationships among the resilience factors.

\section{References}

Akgun, A.E and Lynn, G.S. (2002) 'Antecedents and consequences of team stability on new product development performance', Journal of Engineering and Technology Management, Vol. 19, No. 3-4, pp.263-286. 
Building theory of agri-food supply chain resilience using Total Interpretive Structural Modelling and MICMAC analysis

Attri, R., Dev, N. and Sharma, V. (2013) 'Interpretive structural modelling (ISM) approach: An overview', Research Journal of Management Sciences, Vol. 2, No. 2, pp.3-8.

Aung, M.M. and Chang, Y.S. (2014) 'Traceability in a food supply chain: Safety and quality perspectives', Food Control, Vol. 39, pp.172-184.

Barratt, M., Choi, T.Y. and Li, M. (2011) 'Qualitative case studies in operations management: Trends, research outcomes, and future research implications', Journal of Operations Management, Vol. 29, No. 4, pp.329-342.

Blackhurst, J., Dunn, K.S. and Craighead, C.W. (2011) 'An Empirically Derived Framework of Global Supply Resiliency', Journal of Business Logistics, Vol. 32, No. 4, pp. 374-391.

Bosona, T. and Gebresenbet, G. (2013) 'Food traceability as an integral part of logistics management in food and agricultural supply chain', Food Control, Vol. 33, No. 1, pp.32-48.

Braun, V. and Clarke, V. (2006) 'Using thematic analysis in psychology', Qualitative research in psychology, Vol. 3, No. 2, pp.77-101.

Cao, M., Vonderembse, M.A., Zhang, Q. and Ragu-Nathan, T.S. (2010) 'Supply chain collaboration: conceptualisation and instrument development', International Journal of Production Research, Vol. 48, No. 22, pp.6613-6635.

Carley, K. (1992) 'Organizational learning and personnel turnover', Organization Science, Vol. 3, No. 1, pp. 20-46.

Charmaz, K. (2014) Constructing grounded theory, SAGE, London.

Choi, T.Y., Hong, Y. (2002) 'Unveiling the structure of supply networks: case studies in Honda, Acura and DaimlerChrysler', Journal of Operations Management, Vol. 20, pp. 469-493.

Christopher, M. (2005) Logistics and supply chain management: creating value-added networks, Pearson Education, Harlow.

Christopher, M. and Peck, H. (2004) 'Building the resilient supply chain', The International Journal of Logistics Management, Vol. 15, No. 2, pp.1-14.

Creswell, J.W. and Poth, C.N. (2018) Qualitative inquiry and research design: choosing among five approaches, SAGE: London.

Demmer, W.A., Vickery, S.K. and Calantone, R. (2011) 'Engendering resilience in small and medium-sized enterprises (SMEs): a case study of Demmer Corporation', International Journal of Production Research, Vol. 49, No. 18, pp.5395-5413.

Faisal, M.N., Banwet, D.K. and Shankar, R. (2007) 'Information risks management in supply chains: an assessment and mitigation framework', Journal of Enterprise Information Management, Vol. 20, No. 6, pp.677-699.

Faisal, M.N., Banwet, D.K. and Shankar, R. (2006) 'Mapping supply chains on risk and customer sensitivity dimensions', Industrial Management \& Data Systems, Vol. 106, No. 6, pp.878-895.

Francis, V. (2008) 'Supply chain visibility: lost in translation?', Supply Chain Management: An International Journal, Vol. 13, No. 3, pp. 180-184.

Golgeci, I. and Ponomarov, S.Y. (2013) 'Does firm innovativeness enable effective responses to supply chain disruptions? An empirical study', Supply Chain Management: An International Journal, Vol. 18, No. 6, pp.604-617.

Jain, V., Kumar, S., Soni, U. and Chandra, C. (2017) 'Supply chain resilience: model development and empirical analysis', International Journal of Production Research, Vol. 55, No. 22, pp.6779-6800. 
Kamalahmadi, M. and Parast, M.M (2016) 'A review of the literature on the principles of enterprise and supply chain resilience: Major findings and directions for future research', International Journal of Production Economics, Vol. 171, pp.116-133.

Kembro, J., Naslund, D. and Olhager, J. (2017) 'Information sharing across multiple supply chain tiers: A Delphi study on antecedents', International Journal of Production Economics, Vol. 193, pp.77-86.

King, N. and Horrocks, C. (2010) Interviews in qualitative research, SAGE, London.

Leat, P. and Revoredo-Giha, C. (2013) 'Risk and resilience in agri-food supply chains: the case of the ASDA PorkLink supply chain in Scotland', Supply Chain Management: An International Journal, Vol. 18, No. 2, pp.219-231.

Macdonald, J.R., Zobel, C.W, Melnyk, S.A. and Griffis, S.E. (2018) 'Supply chain risk and resilience: theory building through structured experiments and simulation', International Journal of Production Research, Vol. 56, No. 12, pp.4337-4355.

Matopoulos, A., Vlachopoulou, M. and Manthou, V. (2007) 'A conceptual framework for supply chain collaboration: empirical evidence from the agri-food industry', Supply Chain Management: An International Journal, Vol. 12, No. 3, pp.177-186.

Maxim, P.S. (1999) Quantitative research methods in the social sciences, New York, Oxford University Press.

Min, S., Roath, A.S., Daugherty, P.J., Genchev, S.E., Chen, H., Arndt, A.D., Richey, R.G. (2005) 'Supply chain collaboration: what's happening?', The International Journal of Logistics Management, Vol. 16, No. 2, pp.237-256.

Pettit, T.J., Fiksel, J. and Croxton, K.L. (2010) 'Ensuring supply chain resilience: development of a conceptual framework', Journal of Business Logistics, Vol. 31, No. 1, pp.1-21.

Pereira, C.R. and Silva, A.L. (2015) 'Key organisational factors for building supply chain resilience: A multiple case study of buyers and suppliers', Journal of Operations and Supply Chain Management, Vol. 8, No. 2, pp.77-95.

Ponomarov, S.Y. and Holcomb, M.C. (2009) 'Understanding the concept of supply chain resilience', The International Journal of Logistics Management, Vol. 20, No. 1, pp.124-143.

Prosperi, P., Allen, T., Padilla, M., Peri, L., Cogill, B. (2014) 'Sustainability and Food \& Nutrition Security: A Vulnerability Assessment Framework for the Mediterranean Region', SAGE Open, Vol. 4, No. 2, pp.1-15.

Reinmoeller, P. and van Barrdwijk, N. (2005) 'The link between diversity and resilience', MIT Sloan Management Review, Vol. 46, No. 4, pp.61-65.

Ringsberg, H. (2014) 'Perspectives on food traceability: a systematic literature review', Supply Chain Management: An International Journal, Vol. 19, No. 5/6, pp.558-576.

Robson, C. (2002) Real World Research, Oxford, Blackwell.

Sandbhor, S and Botre, R. (2014) 'Applying total interpretive structural modelling to study factors affecting construction labour productivity', Australasian Journal of Construction Economics and Building, Vol. 14, No. 1, pp.20-31.

Santos-Vijande, M.L. and Alvarez-Gonzalez, L.I. (2007) 'Innovativeness and organizational innovation in total quality oriented firms: The moderating role of market turbulence', Technovation, Vol. 27, No. 9, pp.514-532.

Saunders, M., Lewis, P. and Thornhill, A. (2012) Research methods for business students, 6th ed., England, Pearson.

Scholten, K. and Schilder, S. (2015) 'The role of collaboration in supply chain resilience', Supply Chain Management: An International Journal, Vol. 20, No. 4, pp.471-484. 
Building theory of agri-food supply chain resilience using Total Interpretive Structural Modelling and MICMAC analysis

Scholten, K., Scott, P.S. and Fynes, B. (2014) 'Mitigation processes - antecedents for building supply chain resilience', Supply Chain Management: An International Journal, Vol. 19, No. 2, pp.211-228.

Sharma, H.D., Gupta, A.D. and Sushil. (1995) 'The Objectives of Waste Management in India: A Futures Inquiry', Technological Forecasting and Social Change, Vol. 48, No. 3, pp.285-309.

Shibin, K.T., Gunasekaran, A., Papadopoulos, T., Dubey, R., Singh, M., Wamba, S.F. (2016) 'Enablers and Barriers of Flexible Green Supply Chain Management: A Total Interpretive Structural Modelling Approach', Global Journal of Flexible Systems Management, Vol. 17, No. 2, pp.171-188.

Simatupang, T.M. and Sridharan, R. (2002) 'The Collaborative Supply Chain', The International Journal of Logistics Management, Vol. 13, No. 1, pp.15-30.

Sindhwani, R. and Malhotra, V. (2017) 'A framework to enhance agile manufacturing system: A total interpretive structural modelling (TISM) approach', Benchmarking: An International Journal, Vol. 24, No. 2, pp.467-487.

Soni, U., Jain, V. and Kumar, S. (2014) 'Measuring supply chain resilience using a deterministic modelling approach', Computers \& Industrial Engineering, Vol. 74, pp.11-25.

Stank, T.P., Keller, S.B. and Daugherty, P.J. (2001) 'Supply chain collaboration and logistical service performance', Journal of Business Logistics, Vol. 22, No. 1, pp.2948.

Sushil. (2012) 'Interpreting the interpretive structural model', Global Journal of Flexible Systems Management, Vol. 13, No. 2, pp.87-106.

Tashakkori, A. and Teddlie, C. (2008) 'Introduction to mixed method and mixed model studies in the social and behavioural sciences', in Clark, V.L.P. and Creswell, J.W (Eds), The mixed methods reader. SAGE, London, pp.5-6.

Tendall, D.M., Joerin, J., Kopainsky, B., Edwards, P., Shreck, A., Le, Q.B., Kruetli, P., Grant, M., Six, J. (2015) 'Food system resilience: Defining the concept', Global Food Security, Vol. 6, pp.17-23.

Van Wijk, R., Jansen, J.J.P. and Lyles, M.A. (2008) 'Inter- and Intra-Organisational Knowledge Transfer: A Meta-Analytic Review and Assessment of its Antecedents and Consequences', Journal of Management Studies, Vol. 45, No. 4, pp.830-853.

Waters, D. (2007) Supply chain risk management: vulnerability and resilience in logistics, Kogan Page Limited, London. 